Chugai, Eisai, Mitsubishi-Tanabe and Novartis, Consultant of:Abbvie, Boehringer, Celgene, Eli Lilly, Janssen, Novartis, Sanofi, UCB, Speakers bureau: Abbvie, Asahi-Kasei, BMS, Chugai, Eisai, Eli Lilly, Janssen, Mitsubishi-Tanabe, Novartis and Pfizer

DOI: 10.1136/annrheumdis-2020-eular.5598

\section{AB1124 USEFULNESS OF SUPERB MICRO-VASCULAR IMAGING(SMI) TO DETECT SILENT VASCULITIC DISEASE ACTIVITY IN 2 CASES OF TAKAYASU ARTERITIS}

Y. Okada ${ }^{1}$, T. Kondo ${ }^{1}$, A. Shibata ${ }^{1}$, K. Chino ${ }^{1}$, T. Kurasawa ${ }^{1}$, K. Amano ${ }^{1}$

${ }^{1}$ Saitama Medical Center, Kawagoe, Japan

Background: It is important to use vascular imaging modalities such as CT, MRI and PET-CT to evaluate disease activity of Takayasu arteritis (TAK). In particular, under treatment with tocilizumab (TCZ), redsidual vasculitic disease activity may remain even if serum CRP becomes negative. Contrast-enhanced CT,MRI and PET-CT can evaluate the morphology of blood vessel walls and the distribution of lesions and vasculitic activity, but it is invasive (radiation or contract media exposure), and costly. Ultrasound is superior in terms of morphological evaluation, cost, convenience, and low invasiveness. In particular, Superb Micro-vascular Imaging(SMI) is one of the micro blood flow display methods that can be installed in the ultrasound diagnostic device Aplio series.

There are some case reports in which micro blood flow signals of the carotid artery walls were detected using SMI in Takayasu arteritis [1] [2]. Both reports indicate that SMI blood flow is a comparable indicator of disease activity as serum CRP.

Objectives: To report the usefulness of SMI in 2 TAK patients who had negative serum CRP but had residual disease activity, leading to appropriate adjustment of treatment.

Methods: Two TAK patients who had been newly diagnosed in our department from May 2015 to October 2018 and had received SMI to detect carotid artery wall blood flow signal were retrospectively analyzed.

Results: Case 1

A 32-year-old woman developed neck pain, headaches, fever and she had high serum levels of CRP $(8.1 \mathrm{mg} / \mathrm{dl})$ and elevated ESR $(98 \mathrm{~mm} / \mathrm{h})$. Contrast-enhanced CT showed thickening of the carotid artery, left subclavian artery and thoracic aorta and SMI detected blood flow signal in carotid artery wall. Diagnosis of TAK was made. After 2-week treatment with $1 \mathrm{mg} / \mathrm{kg} /$ day of PSL, CRP became negative but the micro blood flow in carotid arterity walls was detedted by SMI. Therefore,subcutaneous TCZ (162 mg/week)was added in combination with PSL.One year later, micro blood flow disappeared and we could judge there was no vasculitis activity (Figure $A$ ).

\begin{tabular}{lccc}
\hline & $\begin{array}{c}\text { Before treatment } \\
\text { starts }\end{array}$ & $\begin{array}{c}2 \text { weeks after starting } \\
\text { treatment }\end{array}$ & $\begin{array}{c}\text { One year after starting } \\
\text { treatment }\end{array}$ \\
\hline treatment & - & $\mathrm{PSL} 1 \mathrm{mg} / \mathrm{kg} /$ day ongoing & $\mathrm{PSL} 7 \mathrm{mg} /$ day ongoing \\
$\mathrm{TCZ} 162 \mathrm{mg} /$ week ongoing \\
$\mathrm{CRP}(\mathrm{mg} / \mathrm{dl})$ & $+(8.1)$ & $-(0.0)$ & $-(0.0)$ \\
$\mathrm{SMl}$ signal & + & + & - \\
\hline
\end{tabular}

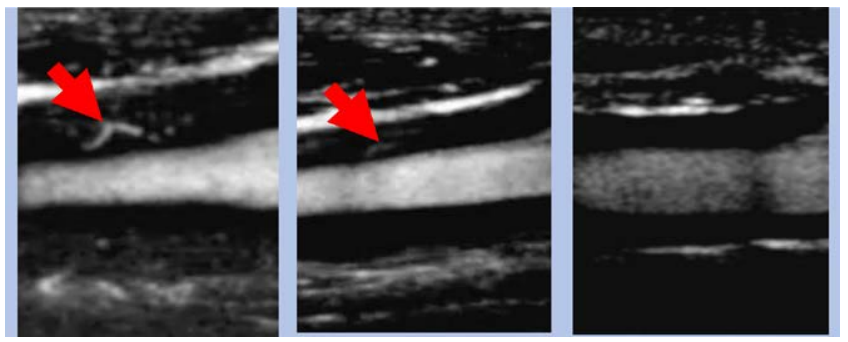

Figure 1. A. Clinical course of Case 1

Case 2

A 17-year-old woman developed proximal upper limb pain and fever with high serum CRP levels $(7.1 \mathrm{mg} / \mathrm{dl})$ and elevated ESR $(>110 \mathrm{~mm} / \mathrm{h})$, and contrast-enhanced CT showed thickening of the carotid arteries and aortic arch. Two weeks after the start of PSL ( $1 \mathrm{mg} / \mathrm{kg} /$ day), CRP became negative at $0.3 \mathrm{mg} / \mathrm{dl}$, but intramural blood flow detected by SMI remained. Then subcutaneous TCZ was added. Two weeks later, CRP became negative, and the SMI blood flow also disappeared (Figure B).

\begin{tabular}{|c|c|c|c|}
\hline & $\begin{array}{l}\text { Before treatment } \\
\text { starts }\end{array}$ & $\begin{array}{c}2 \text { weeks after starting } \\
\text { treatment }\end{array}$ & $\begin{array}{c}4 \text { weeks after starting } \\
\text { treatment }\end{array}$ \\
\hline treatment & - & PSL $1 \mathrm{mg} / \mathrm{kg} /$ day ongoing & $\begin{array}{l}\text { PSL } 50 \mathrm{mg} / \text { day ongoing } \\
\text { TCZ } 162 \mathrm{mg} / \text { week added }\end{array}$ \\
\hline $\mathrm{CRP}(\mathrm{mg} / \mathrm{dl})$ & $+(7.1)$ & $-(0.3)$ & $-(0.0)$ \\
\hline SMI signal & + & + & - \\
\hline
\end{tabular}
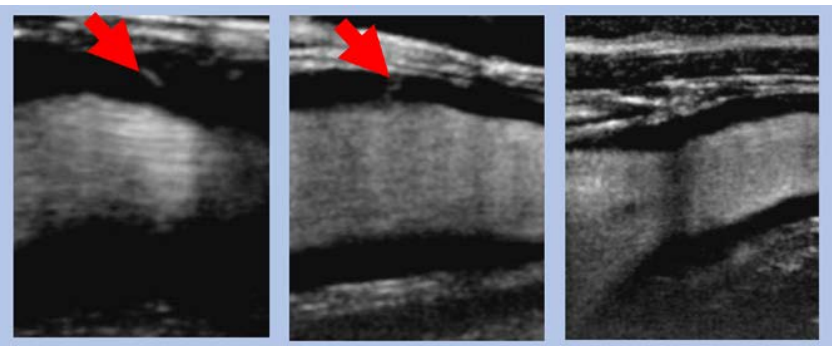

Figure 2. B. Clinical course of Case 2

Conclusion: Although SMI has the limitation that it cannot evaluate deep vascular lesions such as aorta, it is neither invasive nor costly and may be a good tool for evaluation of residual vasculitis activity of TAK.

\section{References:}

[1] Sato W, Sato T, lino T, Seki K, Watanabe H. Visualization of arterial wall vascularization using superb microvascular imaging in active-stage Takayasu arteritis. European Heart Journal - Cardiovascular Imaging 2019;20(6):719

[2] Ito S, Tahara N, Hirakata S, et al. Signal intensity of superb micro-vascular imaging associates with the activity of vascular inflammation in Takayasu arteritis. Journal of Nuclear Cardiology: Official Publication of the American Society of Nuclear Cardiology. 2019 Mar DOI: 10.1007/ s12350-019-01665-4

Acknowledgments: We thank Minako.Yamashita and Masahiro.setoyama for her technical assistance to conduct SMI.

Disclosure of Interests: None declared

DOI: 10.1136/annrheumdis-2020-eular.1806

\section{\begin{tabular}{|l|l} 
AB1125 & PERFORMANCE OF ULTRASOUNDS TO
\end{tabular} ASSESS EROSION PROGRESSION IN RHEUMATOID ARTHRITIS}

M. Peran ${ }^{1}$, E. Allado ${ }^{1}$, E. Albuisson ${ }^{1}$, M. Couderc ${ }^{2}$, P. Ornetti ${ }^{3}$, C. Roux ${ }^{4}$,

J. Grosse ${ }^{1}$, I. Chary Valckenaere ${ }^{1}$, D. Loeuille ${ }^{1}{ }^{1}$ CHRU Nancy, NANCY, France;

${ }^{2} \mathrm{CHU}$ Gabriel-Montpied, Clermont-Ferrand, France; ${ }^{3} \mathrm{CHU}$ Dijon Bourgogne,

Dijon, France; ${ }^{4}$ HPM Belle Isle, Metz, France

Background: Ultrasonography (US) can detect more erosions than radiography $(R X)$ at the joint level in rheumatoid arthritis (RA), especially at an early stage of the disease.

Objectives: The aim of the study is to determine the ability of ultrasonography to detect erosion progression by the US Score for erosions (USSe), in early (less than 2 years disease duration (DD)) and late stage (more than 2 years DD) RA over two years of follow-up.

Methods: Patients fulfilling ACR 1987 and/or ACR/EULAR 2010 criteria for RA were prospectively included. Clinical and demographic informations were recorded at baseline and hands and feet $\mathrm{RX}$ were scored according to the Sharp erosion score (SHSe). Erosive RA on RX was defined by the presence of at least three eroded joints (1). US examinations were performed at baseline and during the two years of follow-up. Erosions were scored by US on six bilateral joints (MCP 2, 3, 5 and MTP 2, 3,5) with a four grade-scale to calculate total USSe. Erosive RA on US was defined by presence of one erosion $\geq 2 \mathrm{~mm}$ (2). Inter-examiner reproducibility was performed on 14 patients in order to calculate the smallest detectable change (SDC), which was 2.3. Ultrasonographic progression was defined as a change in USSe $>2$ (erosion change $>$ SDC).

Results: A total of 71 patients were included, 22 patients $(31.0 \%)$ had early RA and 49 (69.0\%) patients had late RA diseases. On RX, 30 (42.3\%) patients were erosive at baseline with a mean SHSe at 29.4 (SD at 24.7). 
On US, 63 patients $(88.7 \%)$ were classified as eroded. On US, erosions prevailed at baseline in MTP5 joints, then MCP2 and MCP5 joints on their lateral facets. During follow-up, 28 patients $(39.4 \%)$ were classified as US progressors, $30(42.3 \%)$ were stable and $13(18.3 \%)$ considered as regressors (figure 1). In early RA disease, three of the four non eroded patients became eroded. USSe progressed in 11 patients $(50 \%)$ while regression was observed in only one patient. In late RA disease, 17 patients (34.7\%) progressed and 12 patients $(24.5 \%)$ decreased significantly their USSe. Erosion progression prevailed on MTP 5 joints followed by MCP2 and finally MCP5 joints (figure 2).

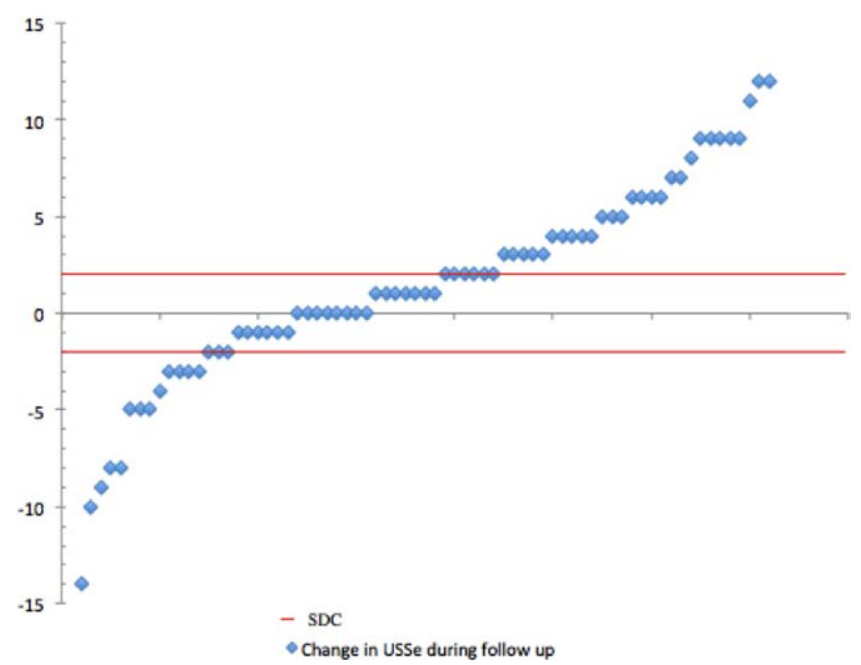

Figure 1. USSe progression plots $(n=71)$

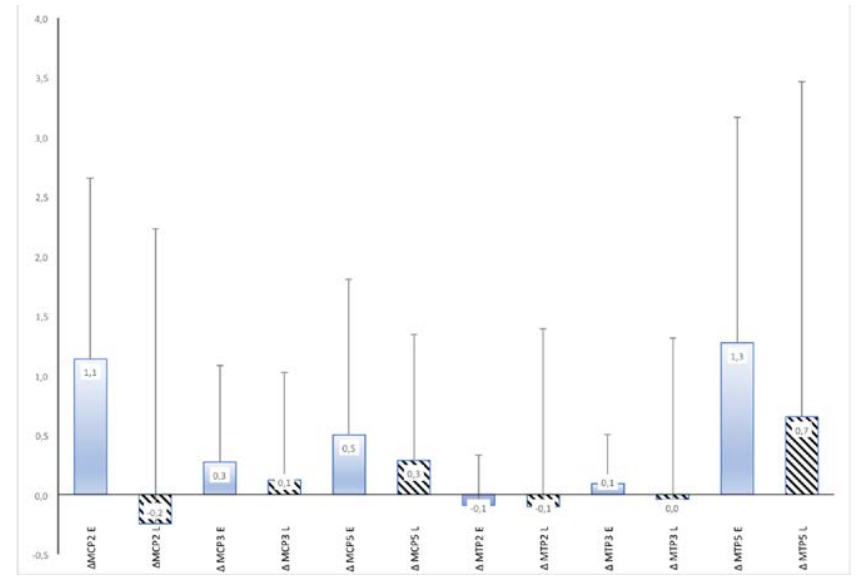

Figure 2. Differences of USSe by joints during follow-up in early and late RA

Conclusion: US structural examination is a highly reproducible method to assess erosion in RA disease. The USSe is able to detect structural changes (progression, stabilization and regression) in RA patients during a follow-up of two years especially in RA patients with short disease duration.

References:

[1] Van der Heijde D, van der Helm-van Mil AHM, Aletaha D, Bingham CO, Burmester GR, Dougados M, et al. EULAR definition of erosive disease in light of the 2010 ACR/EULAR rheumatoid arthritis classification criteria. Ann Rheum Dis. avr 2013;72(4):479-81.

[2] Roux C, Gandjbakhch F, Pierreisnard A, Couderc M, Lukas C, Masri R, et al. Optimization of ultrasonographic examination for the diagnosis of erosive Rheumatoid Arthritis in comparison to erosive hand Osteoarthritis. Eur $\mathrm{J}$ Radiol. sept 2019;118:10-8.

Disclosure of Interests: None declared

DOI: 10.1136/annrheumdis-2020-eular.2444

\section{$\mathrm{AB} 1126$ \\ THE RELIABILITY AND DIAGNOSTIC ACCURACY OF DIGITAL TOMOSYNTHESIS COMPARED WITH CONVENTIONAL RADIOGRAPHY FOR THE INVESTIGATION OF SACROILIITIS}

A. Rischin ${ }^{1}$, E. Kathpal ${ }^{1}$, S. Vogrin ${ }^{2}$, L. Bentley ${ }^{3}$, V. Master ${ }^{3}$, A. Steward ${ }^{3}$, K. Le Marshall ${ }^{1}, \mathrm{~K} . \mathrm{Lim}^{1} .{ }^{1}$ Department of Rheumatology, Western Health, Melbourne, Australia; ${ }^{2}$ University of Melbourne and Western Health, Melbourne, Australia; ${ }^{3}$ Department of Radiology, Western Health, Melbourne, Australia

Background: Conventional radiography remains part of the diagnosis of axial spondyloarthritis and determines qualification for biologic disease modifying anti-rheumatic drugs in many countries. The standard anteroposterior radiograph (XR) incompletely images the complex sacroiliac joint with recognised unacceptably low levels of agreement between readers. Digital tomosynthesis (DTS) uses conventional radiographic projections to create a three-dimensional image and is a potential alternative for the initial radiographic detection and grading of sacroiliitis.

Objectives: To compare the level of agreement between two radiologists when reporting sacroiliac joint imaging with digital tomosynthesis versus conventional radiography, as well as to compare the diagnostic accuracy of each imaging modality.

Methods: 229 consecutive patients that had radiography and digital tomosynthesis performed at Footscray Hospital, Melbourne, Australia were included. Two blinded radiologists independently re-reported all images according to the modified New York criteria, or listed an alternative diagnosis. An overall assessment of each image as inflammatory sacroiliitis, normal or non-inflammatory disease was also recorded. Demographic and clinical data were extracted from medical records. Agreement between and within readers was evaluated using kappa (к) statistic. Diagnostic accuracy was calculated by comparing each reader's overall assessment against 2 reference standard comparators: most recent rheumatologist diagnosis and fulfillment of ASAS criteria at any time point.

Results: The intra-reader agreement of reader 1 was almost perfect for the left, right and overall sacroiliac joint assessments ( $\mathrm{k} 0.77$ - 0.94), with DTS outperforming XR. Reader 2 agreement was mostly moderate ( $\mathrm{k} 0.39-0.69$ ), with DTS and XR better on the left and right sacroiliac joint respectively, but XR having better overall assessment. The inter-reader agreement of DTS for all patients was moderate and better than XR as shown in the Table. When excluding non-spondyloarthritis patients, inter-reader agreement improved ( $\mathrm{k} 0.50$ to 0.58 ) but there was no significant difference between DTS and XR. Using reader 1 , the sensitivity of DTS $(64.8-66.7 \%)$ was better than XR $(54.9-60.7 \%)$ but low, in keeping with what is known about radiographic sacroilitis and axial spondyloarthritis. The specificity of XR (78.5-80.3\%) was better than DTS $(72.3-73.1 \%)$. There were no significant differences when fulfillment of modified New York Criteria was used as a reader's positive test.

Table. Inter-rater reliability between the readers

\begin{tabular}{lccc}
\hline & $\begin{array}{c}\text { All patients } \\
(\mathrm{N}=229)^{*}\end{array}$ & $\begin{array}{c}\text { Inflammatory sacroilitis \& normal } \\
\text { patients }(\mathrm{N}=164)^{* *}\end{array}$ & $\begin{array}{c}\text { Inflammatory sacroilii- } \\
\text { tis patients }(\mathrm{N}=92)^{* *}\end{array}$ \\
\hline XR Right & 0.36 & 0.52 & 0.56 \\
DTS Right & 0.39 & 0.50 & 0.51 \\
XR Left & 0.34 & 0.55 & 0.56 \\
DTS Left & 0.42 & 0.55 & 0.58 \\
XR Overall & 0.40 & & \\
DTS Overall & 0.45 & & \\
\hline
\end{tabular}

Non-weighted kappa statistic

"Weighted kappa statistic

Conclusion: DTS demonstrated moderate reliability for assessment of sacroiliitis, marginally better than conventional radiography. Overall levels of agreement for both imaging modalities were however lower than radiography in previous studies, with several possible contributing factors. A prospective study in a selected spondyloarthritis cohort may better determine any benefit of DTS.

References:

[1] Christiansen AA, Hendricks O, Kuettel D, Horslev-Petersen K, Jurik AG, Nielsen S, et al. Limited Reliability of Radiographic Assessment of Sacroiliac Joints in Patients with Suspected Early Spondyloarthritis. The Journal of rheumatology. 2017;44(1):70-7.

[2] van Tubergen A, Heuft-Dorenbosch L, Schulpen G, Landewe R, Wijers R van der Heijde D, et al. Radiographic assessment of sacroiliitis by radiologists and rheumatologists: does training improve quality? Annals of the rheumatic diseases. 2003;62(6):519-25.

Disclosure of Interests: None declared

DOI: 10.1136/annrheumdis-2020-eular.3521 